Article

\title{
Microwave Assisted Extraction of Phenolic Compounds from Four Different Spices
}

\author{
Monica Gallo, Rosalia Ferracane, Giulia Graziani *, Alberto Ritieni and Vincenzo Fogliano \\ Department of Food Science, University of Naples “Federico II”, Via Università 100, Parco Gussone \\ Ed.84, 80055, Portici, Naples, Italy
}

* Author to whom correspondence should be addressed; E-Mail: giulia.graziani@unina.it; Tel.: +39812539351; Fax: +39817762580.

Received: 9 July 2010; in revised form: 28 July 2010 / Accepted: 30 July 2010 /

Published: 9 September 2010

\begin{abstract}
Spices and herbs are known not only for their taste, aroma and flavour, but also for their medical properties and value. Both spices and herbs have been used for centuries in traditional medical systems to cure various kinds of illnesses such as common cold, diabetes, cough and cancers. The aim of this work was the comparison between two different extractive techniques in order to get qualitative and quantitative data regarding bioactive compounds of four different spices (Cinnamomum zeylanicum, Coriandrum sativum, Cuminum cyminum, Crocus sativus). The plants were extracted employing ultrasonication and microwave-assisted extractions. The efficiency of extraction of bioactive compounds obtained with the microwave extraction process was in general about four times higher than that resulting from sonication extraction. The various extracts obtained were analyzed for their antioxidant activity using ABTS, DPPH and FRAP assays and for their total polyphenolic content. It can be concluded that microwave-assisted extractions provide significant advantages in terms of extraction efficiency and time savings.
\end{abstract}

Keywords: spices; antioxidant activity; phenolic compounds; MAE; food composition 


\section{Introduction}

Spices and herbs have been investigated for their antioxidant properties for at least 50 years, in particular, spices are known to possess a variety of antioxidant effects and properties [1,2]. In recent decades, a number of phenolic substances were isolated from a variety of spice sources, including phenolic acids, flavonoids, phenolic diterpenes and volatile oils [3-6]. Phenolic compounds in these plant materials are closely associated with their antioxidant activity. They are also known to play an important role in stabilizing lipid peroxidation and to inhibit various types of oxidizing enzymes [7,8].

This antioxidant action make the diverse group of phenolic compounds an interesting target in the search for health-beneficial phytochemicals and also offer a possibility to use phenolic compounds or extracts rich in them in lipid-rich foods to extend shelf life [9], indeed the presence of antioxidative and antimicrobial phenolic constituents in many spices gives food-preserving properties [10,11].

Flavonoids and other plant phenolics, such as phenolic acids, stilbenes, tannins, lignans and lignin are especially common in leaves, flowering tissues and woody parts such as stems and barks [12]. They generally occur as glycosylated derivates in plants, although conjugation with inorganic sulfate or organic acids as well as malonylation are also known [13]. The antioxidant activity of phenolics is mainly due to their redox properties, which allow them to act as reducing agents, hydrogen donors and singlet oxygen quenchers. In addition, they have a metal chelation potential [14].

Several extraction techniques and solvents are used for obtaining antioxidant extracts from plant sources. Extraction techniques include solvent extraction (SE) [15], microwave assisted extraction (MAE) [16], soxhlet extraction and supercritical fluid extraction [17]. Among these, MAE is a relatively new method used for the extraction of natural products [18]. Pan et al., [19] had earlier shown that MAE was more effective than conventional extraction methods in the extraction of tea polyphenols and tea caffeine. Hong et al. used MAE to optimize the extraction of phenolic compounds from grape seeds [20].

A recent paper in the literature [21], reports that the best extraction of phytocomponents from flowering tops of Melilotus officinalis was obtained employing 50\% aqueous ethanol either with microwave assisted extraction or with ultrasound assisted extraction. Waksmundzka-Hajnos et al., [22] studied the optimal conditions for the extraction of furanocoumarins from fruits of Archangelica officinalis and concluded that some compounds such as imperatorin and phellopterin may be transformed during pressurised microwave assisted extraction; therefore the MAE cannot be considered an advisable method for the furanocoumarin recovery.

Ganzler et al., [18] showed that a microwave-assisted extraction system for biologically active compounds has many advantages over other conventional extraction methods. Microwave-assisted extraction methods required shorter time, less solvents, provide higher extraction rates and better products with lower costs. Numerous biologically active compounds have been extracted by application of microwave-assisted extraction, such as extraction of taxanes from Taxus brevifolia needles [23], extraction of azadiractine related limonoids from Azadirachta indica seed kernels [24], extraction of glycyrrhizic acid from Glycyrrhizia glaubra root [25], extraction of tanshinones from Salvia miltorrhiza bung [26], extraction of artemisinin from Artemisia annua [27] and extraction of ginsenosides from Panax ginseng root [28]. 
The aim of this work was the comparison between two different extractive techniques in order to study the qualitative and quantitative data regarding bioactive compounds of four different spices (Cinnamomum zeylanicum, Coriandrum sativum, Cuminum cyminum, Crocus sativus). The plants were extracted employing ultrasonication and microwave-assisted extractions.

\section{Results and Discussion}

\subsection{Total phenols and antioxidant activity}

The optimised extraction conditions used in the MAE were determined after preliminary tests showing that severe conditions of microwave power and temperatures gave recoveries of polyphenol compounds about $30 \%$ lower than ultrasound assisted extraction.

The analysis of total polyphenols (Folin) of different extracts obtained suggested that the microwave-assisted method was more effective compared to the ultrasound extraction method and it could be used as an effective method to extract antioxidant components considering factors such as the extraction time and the solvent wastage. In particular, results showed higher recoveries for Cinnamomum zeylanicum (three times higher), Cuminum cyminum (four times higher), Crocus sativus (six times higher), while for Coriandrum sativum no significative differences between the two methods have been found. Our data shown that the amount of total phenolics varied widely in spice samples analyzed and ranged from 41 to $2939 \mathrm{mg} \mathrm{GAE} / 100 \mathrm{~g}$ dry material (Table 1) between two techniques. (Table 1).

Table 1. Total phenolic contents of spice extracts obtained with ultrasound and microwave assisted extraction.

\begin{tabular}{|l|c|c|}
\hline \multirow{2}{*}{ Sample } & \multicolumn{2}{|c|}{$\begin{array}{c}\text { Total phenolic content } \\
\text { (mg gallic acid/100 g) }\end{array}$} \\
\cline { 2 - 3 } & UAE & MAE \\
\hline Coriandrum sativum & $41,812 \pm 2,765$ & $82,091 \pm 8,432$ \\
\hline $\begin{array}{l}\text { Cinnamomum } \\
\text { zeylanicum }\end{array}$ & $506,597 \pm 23,518$ & $1679,201 \pm 65,333$ \\
\hline Cuminum cyminum & $290,296 \pm 13,545$ & $1159,542 \pm 21,239$ \\
\hline Crocus sativus & $500,213 \pm 34,745$ & $2939,472 \pm 24,610$ \\
\hline
\end{tabular}

Table 2. Antioxidant activity of spice extracts obtained with ultrasound and microwave assisted extraction.

\begin{tabular}{|l|c|c|c|c|c|c|}
\hline \multirow{2}{*}{ Sample } & \multicolumn{2}{|c|}{$\begin{array}{c}\text { Antioxidant activity } \\
\text { (ABTS) } \\
\text { mmol Trolox }\end{array}$} & \multicolumn{2}{c|}{$\begin{array}{c}\text { Antioxidant activity } \\
\text { (DPPH) } \\
\text { \% inhibition }\end{array}$} & \multicolumn{2}{c|}{$\begin{array}{c}\text { Antioxidant activity } \\
\text { (FRAP) }\end{array}$} \\
& UAE & MAE & UAE & MAE & UAE & MAE \\
\cline { 2 - 7 } & 0,080 & 0,035 & 74,379 & 25,565 & 1,198 & 68,765 \\
\hline $\begin{array}{l}\text { Coriandrum } \\
\text { sativum }\end{array}$ & 1,271 & 3,172 & 90,451 & 91,789 & 8,176 & 240,045 \\
\hline $\begin{array}{l}\text { Cinnamomum } \\
\text { zeylanicum }\end{array}$ & 0,217 & 2,671 & 85,432 & 88,432 & 50,345 & 140,319 \\
\hline $\begin{array}{l}\text { Cuminum } \\
\text { cyminum }\end{array}$ & 0,045 & 1,258 & 15,692 & 19,673 & 8,450 & 391,123 \\
\hline Crocus sativus & & & & &
\end{tabular}


In hydroalcoholic conventional extracts of Crocus sativus total antioxidant concentration was of $500.21 \mathrm{mg} / 100 \mathrm{~g}$ on dry weight, this result was according with literature data which reported amount of polyphenolic compounds of $526.72 \mathrm{mg} / 100 \mathrm{~g}$ on dry weight [29].

For Cuminum cyminum the values reported in literature for total polyphenols in hydroalcoholic extracts were of $230 \mathrm{mg} / 100 \mathrm{~g}$ dry weight and were comparable to the values obtained in our ultasound assisted extracts that showed an amount of total phenols of $290.29 \mathrm{mg} / 100 \mathrm{~g}$ dry weight [30].

The total phenolic content for Cinnamomum zeylanicum was $507 \mathrm{mg} / 100 \mathrm{~g}$ on dry weight, with respect to $49 \mathrm{mg} / 100 \mathrm{~g}$ dry weight reported in literature [31] for barks. Our value was referred to leaves and was in accordance with the results showed by Prasad et al., regarding the flavonoid contents and antioxidant activities from Cinnamomum species [32].

Coriandrum sativum showed a value of $41.81 \mathrm{mg} / 100 \mathrm{~g}$ of dry weight, a concentration that was low if compared with values reported in literature [32,33], which amounted to $520 \mathrm{mg} / 100 \mathrm{~g}$ dry weight for the whole plant and $880 \mathrm{mg} / 100 \mathrm{~g}$ dry weight for the leaves. On the other hand, the values reported in our study referred to seeds and not to entire plants or leaves as in literature.

The four species were rich in phenolic constituents and demonstrated good antioxidant activity measured by different methods. The antioxidant activity was carried out using ABTS [37], DPPH [38] and FRAP assays [39], which determined the disappearance of free radical solutions using a spectrophotometer.

The antioxidant activity evaluated with the ABTS test allowed us to obtain the results reported in Table 2. In particular, Cinnamomum zeylanicum, Cuminum cyminum and Crocus sativus microwaveassisted extracts have a strong antioxidant activity compared to ultrasound assisted extracts, while for Coriandrum sativum the conventional extraction allows to obtain more effective extracts in terms of antioxidant capacity.

Among the different matrices analyzed, Cinnamomum zeylanicum, extracted with microwaves shows the greatest antioxidant activity measured by the ABTS assay $\left(3.17 \mathrm{mmol}\right.$ Trolox $\left.{ }^{\circledR} / 100 \mathrm{~g}\right)$, while the seeds of Coriandrum sativum, extracted with microwave, are those who have the lowest antioxidant activity $\left(0.035 \mathrm{mmol}\right.$ Trolox $\left.{ }^{\circledR} / 100 \mathrm{~g}\right)$. On the other hand, microwave-assisted extract of Crocus sativus, showed an antioxidant effectiveness 28 times higher than the extract obtained with ultrasound assisted extraction considering the ABTS assay. In the literature 1,243 $\mu$ mol Trolox ${ }^{\circledR} / 100 \mathrm{~g}$ of dry weight and 1,064 $\mu \mathrm{mol} / 100 \mathrm{~g}$ of dry weight were reported for the acetonic and methanolic extracts of Cinnamomum zeylanicum, respectively [33]. As shown in Table 2 the values obtained in the ultrasound assisted extracts are in accordance with the literature data.

In the case of DPPH, the values of antioxidant activity of Cinnamomum zeylanicum, Cuminum cyminum and Crocus sativus extracts obtained from the two extractive techniques are comparable, while for Coriandrum sativum the antioxidant activity of ultrasound assisted extract was almost three times greater than the microwave assisted extract (Table 2). This result could be due to different affinities of Coriandrum sativum antioxidant compounds presents in ultrasound assisted extract towards DPPH radical species. In literature, Politeo et al. [34] reported an antioxidant activity value of 57.75 measured with the DPPH assay expressed as an inhibition percentage for Coriandrum sativum extracts, while Tomaino et al. [35] reported in Cinnamomum zeylanicum extracts a percentage of inhibition of 55.30. Our extracts obtained with ultrasound assisted process have an antioxidant activity expressed as inhibition percentage of 74.37 in Coriandrum sativum and 90.45 in Cinnamomum 
zeylanicum, therefore our results show high inhibition percentage values, probably due to the diversity of origin and/or cultivars of matrix analyzed.

The data obtained with FRAP assay are represented in Table 2. All spices analyzed showed an antioxidant activity highest for the microwave-assisted extraction. Among the samples analyzed, the microwave-assisted extract of Crocus sativus showed the highest antioxidant activity (391 mmol Trolox $\AA / 100 \mathrm{~g}$ ), while Coriandrum sativum had the lowest antioxidant activity (68 mmol Trolox $® / 100 \mathrm{~g})$.

The results allow us to claim that the microwave-assisted extraction is a particularly advantageous technique especially for Crocus sativus, which had an antioxidant activity about 45 times higher than ultrasound assisted extract. In the literature it was reported that Crocus sativus extract showed a total antioxidant activity calculated as sum of hydrophilic and lipophilic antioxidant activity of about $73.94 \mathrm{mmol}$ of $\mathrm{Fe}^{2+} / 100 \mathrm{~g}$ dry weight [36]. Our results obtained for ultrasound extracts showed an antioxidant activity expressed as mmol of Trolox ${ }^{\circledR} / 100 \mathrm{~g}$ of dry matter of 8.45 ; this result allow to assert that Crocus sativus was the matrix best extracted using microwaves, probably for its typical structure that enables an advantageous recovery of bioactive metabolites. This result could be attributed to the higher dielectric susceptibility of the matrix and to the better interaction between solvent and the Crocus sativus in MAE conditions. Moreover, crocetins are water soluble compounds esterified with one or two sugar moieties, therefore they easily adsorb microwave energy.

\section{Materials and Methods}

\subsection{Chemicals}

All reagents and solvents HPLC grade were purchased from Merck (Darmstadt, Germany). The spices (Cinnamomum zeylanicum, Coriandrum sativum, Cuminum cyminum, Crocus sativus) were bought in a local market from a specialized retailer of spices for human consumption. Each sample was contained in a small glass bottle sealed with a plastic screw cap. The products, harvested in 2008, were in different forms: minced desiccated leaf samples: Cinnamomum zeylanicum; powdered samples: Crocus sativus stigma; samples of seeds: Coriandrum sativum and Cuminum cyminum.

(S)-(-)-6-Hydroxy-2,5,7,8-tetramethylchroman-2-carboxylic acid (Trolox ${ }^{\circledR}$ ), 2,2'-azino-bis(3-ethylbenzothiazoline-6'-sulfonic acid) diammonium salt (ABTS), gallic acid, potassium persulfate, 2,2diphenyl-1-picrylhydrazyl (DPPH), ferric chloride, Folin Ciocalteau, anhydrous sodium acetate, reagent and 2,4,6-tri(2-pyridyl-s-triazine) (TPTZ), were purchased from Sigma (Milan, Italy), as were caffeic acid, cinnammic acid, chlorogenic acid, quercetin, luteolin, apigenin, quercetinrhamnoglucoside (rutin), luteolin glucoside and apigenin glucoside standards.

\subsection{Microwave-assisted extraction (MAE)}

An ETHOS 1 microwave-oven (Milestone, Shelton, CT, USA) equipped with 10 TFM Teflon closed vessels and a ATC-400FO Automatic Fiber Optic temperature control system was used for microwave assisted extractions (MAE). Extractions were performed at $200 \mathrm{~W}$ and at $50{ }^{\circ} \mathrm{C}$, a magnetic stirring rod was added in each vessel. The spices were extracted using the following method: sample $(1 \mathrm{~g})$ was extracted with ethanol/water $(50: 50 \mathrm{v} / \mathrm{v}, 20 \mathrm{~mL})$, the extractions being carried at $200 \mathrm{~W}$ using magnetic stirring at $50 \%$ of nominal power and a temperature of $50{ }^{\circ} \mathrm{C}$ for $18 \mathrm{~min}$. All samples 
were filtered through a $0.45 \mu \mathrm{m}$ nylon syringe filter (Millipore) before chromatographic and antioxidant analysis. All extractions were performed in triplicate.

\subsection{Ultrasound assisted extraction (UAE)}

Sample (3g) was extracted with ethanol/water $(50: 50 \mathrm{v} / \mathrm{v}, 30 \mathrm{~mL})$, the extractions were performed in a ultrasonic bath (Astrason the Heat System (Germany) with a working frequency of $33 \mathrm{KHz}$. The samples after sonication at room temperature for $30 \mathrm{~min}$, were centrifuged to 4,000 rpm, at $4{ }^{\circ} \mathrm{C}$, filtered with filter paper and analyzed by mass spectrometry. The ultrasonic plant material extraction procedure was repeated three times.

\subsection{Antioxidant activity: ABTS assay}

Antioxidant capacity assay was performed using an UV-VIS recording spectrophotometer (Shimadzu, Japan) by the improved $\mathrm{ABTS}^{+}{ }^{+}$method as described by Re et al. [37]. ABTS ${ }^{+}$radical cation was generated by reacting $7 \mathrm{mM}$ ABTS and $2.45 \mathrm{mM}$ potassium persulfate after incubation at room temperature $\left(23{ }^{\circ} \mathrm{C}\right)$ in dark for $16 \mathrm{~h}$. The ABTS ${ }^{+}$solution was diluted with ethanol to an absorbance of $0.700 \pm 0.050$ at $734 \mathrm{~nm}$. The filtered sample was diluted with $70 \%$ methanol so as to give $20-80 \%$ inhibition of the blank absorbance with $0.1 \mathrm{~mL}$ of sample. ABTS ${ }^{+}$solution $(1 \mathrm{~mL}$, with absorbance of $0.700 \pm 0.050)$ was added to the tested samples $(0.1 \mathrm{~mL})$ and mixed thoroughly. The reactive mixture was allowed to stand at room temperature for $2.5 \mathrm{~min}$ and the absorbance was immediately recorded at $734 \mathrm{~nm}$. Trolox ${ }^{\circledR}$ standard solution (final concentration 0-15 $\mu \mathrm{M}$ ) in methanol was prepared and assayed at the same conditions. The absorbance of the resulting oxidized solution was compared to that of the calibrated Trolox ${ }^{\circledR}$ standard. Results were expressed in terms of Trolox ${ }^{\circledR}$ equivalent antioxidant capacity (TEAC, mmol Trolox ${ }^{\circledR}$ equivalents per $100 \mathrm{~g}$ dry weight of plant).

\subsection{Antioxidant activity: DPPH assay}

The DPPH radical-scavenging activity was determined using the method proposed by Yen and Chen [38]. DPPH $(100 \mu \mathrm{M})$ was dissolved in pure ethanol (96\%). The radical stock solution was prepared fresh daily. The DPPH solution $(1 \mathrm{~mL})$ was added to the polyphenol extract $(1 \mathrm{~mL})$ with ethanol $(3 \mathrm{~mL})$. The mixture was shaken vigorously and allowed to stand at room temperature in the dark for $10 \mathrm{~min}$. The decrease in absorbance of the resulting solution was monitored at $517 \mathrm{~nm}$ at $10 \mathrm{~min}$. The results were corrected for dilution and expressed in $\mu \mathrm{M}$ Trolox ${ }^{\circledR}$ per $100 \mathrm{~g}$ dry weight (dw). All determinations were performed in triplicate.

\subsection{Antioxidant activity: FRAP assay}

This assay was based on the reducing power of antioxidant compouds toward ferric salt [39]. Antioxidants reduce the ferric ion $\left(\mathrm{Fe}^{3+}\right)$ to the ferrous ion $\left(\mathrm{Fe}^{2+}\right)$ and the latter forms was a blue complex $\left(\mathrm{Fe}^{2+} / \mathrm{TPTZ}\right.$ ), which increases the absorption at $593 \mathrm{~nm}$. Briefly, the FRAP reagent was prepared by mixing acetate buffer $(300 \mu \mathrm{M}, \mathrm{pH} 3.6)$, a solution of $10 \mu \mathrm{M}$ TPTZ in $40 \mu \mathrm{M} \mathrm{HCl}$, and $20 \mu \mathrm{M} \mathrm{FeCl}_{3}$ at 10:1:1 (v/v/v). The reagent $(300 \mu \mathrm{L})$ and sample solutions $(10 \mu \mathrm{L})$ were added to each well and mixed thoroughly. The absorbance was taken at $593 \mathrm{~nm}$ after $10 \mathrm{~min}$. Standard curve was 
prepared using different concentrations of Trolox ${ }^{\circledR}$. All solutions were used on the day of preparation. The results were corrected for dilution and expressed in $\mu \mathrm{M}$ Trolox ${ }^{\circledR}$ per $100 \mathrm{~g}$ dry weight (dw). All determinations were performed in triplicate.

\subsection{Determination of total phenolics (Folin-Ciocalteu)}

Total polyphenol content was measured using the Folin-Ciocalteu colorimetric method described previously by Gao et al. [40]. Spice extracts $(100 \mu \mathrm{L})$ were mixed with Folin-Ciocalteu reagent $(0.2 \mathrm{~mL})$ and $\mathrm{H}_{2} \mathrm{O}(2 \mathrm{~mL})$, and incubated at room temperature for $3 \mathrm{~min}$. Following the addition of $20 \%$ sodium carbonate $(1 \mathrm{~mL})$ to the mixture, total polyphenols were determined after $1 \mathrm{~h}$ of incubation at room temperature. The absorbance of the resulting blue colour was measured at $765 \mathrm{~nm}$ with a UV-VIS spectrophotometer. Quantification was done with respect to the standard curve of gallic acid. The results were expressed as gallic acid equivalents (GAE), milligrams per $100 \mathrm{~g}$ of dry weight $(\mathrm{dw})$. All determinations were performed in triplicate $(n=3)$.

\section{Conclusions}

In this study two different methods for the bioactive metabolites extraction (ultrasound and microwave assisted extraction) were compared.

The analysis of total polyphenols (Folin) of various extracts obtained suggested that the microwaveassisted method was more convenient compared to the ultrasound extraction method especially for Cinnamomum zeylanicum, Cuminum cyminum, Crocus sativus, while for Coriandrum sativum no significative differences between the two methods have been found.

The antioxidant activity measured with ABTS, DPPH and FRAP assays activity highlighted that the extracts obtained using microwaves were richer in antioxidant metabolites than those obtained by ultrasonic extraction, being a good source of antioxidants.

The use of MAE in analytical laboratories should increase in the next few years, especially thanks to the reasonable cost of the equipment, suggesting that this field of application should expand in the near future.

\section{References}

1. Shobana, S.; Akhilender Naidu, K. Antioxidant activity of selected Indian spices. Prostagland. Leuk. Essent. Fatty 2000, 62, 107-110.

2. Zheng, W.; Wang, S.Y. Antioxidant activity and phenolic compounds in selected herbs. J. Agric. Food Chem. 2001, 49, 5165-5170.

3. Aruoma, O.I.; Spencer, J.P.E.; Rossi, R.; Aeschbach, R.; Khan, A.; Mahmood, N.; Munoz, A.; Murcia, A.; Butler, J.; Halliwell, B. An evaluation of the antioxidant and antiviral action of extracts of rosemary and provencal herbs. Food Chem. Toxicol. 1996, 34, 449-456.

4. Cuvelier, M.E.; Berset, C.; Richard, H. Antioxidant constituents in sage (Salvia officinalis). J. Agric. Food Chem. 1994, 42, 665-669. 
5. Melo, E.D.; Mancini, J.; Guerra, N.B. Characterization of antioxidant compounds in aqueous coriander extract (Coriandrum sativum L.). Lebensm.-Wiss. Technol.-Food Sci. Technol. 2005, 38, 15-19.

6. Frankel, E.N.; Huang, S.W.; Aeschbach, R.; Prior, E. Antioxidant activity of a rosemary extract and its constituents, carnosic acid, carnosol, and rosmarinic acid, in bulk oil and oil-in-water emulsion. J. Agric. Food Chem. 1996, 44, 131-135.

7. Cos, P.; Ying, L.; Calomme, M.; Hu, J.P.; Cimanga, K.; van Poel, B.; Pieters, L.; Vlietinck, A.J.; Vanden Berghe, D. Structure-activity relationship and classification of flavonoids as inhibitors of xanthine oxidase and superoxide scavengers. J. Nat. Prod. 1998, 61, 71-76.

8. Laughton, M.J.; Evans, P.J.; Moroney, M.A.; Hoult, J.R.S.; Halliwell, B. Inhibition of mammalian 5-lipoxygenase and cyclooxygenase by flavonoids and phenolic dietary additives-Relationship to antioxidant activity and to iron lon-reducing ability. Biochem. Pharmacol. 1991, 42, 1673-1681.

9. Yanishlieva, N.V.; Marinova, E.M. Stabilisation of edible oils with natural antioxidants. Eur. J. Lipid Sci. Technol. 2001, 103, 752-767.

10. Srinivasan, K. Role of spices beyond food flavoring: Nutraceuticals with multiple health effects. Food Rev. Int. 2005, 21, 167-188.

11. Badei, A.Z.M.; El-Akel, A.T.M.; Faheid, S.M.M.; Mahmoud, B.S.M. Application of some spices in flavoring and preservation of cookies: 1-Antioxidant properties of cardamom, cinnamon, and clove. Dtsch. Lebensm.-Rundsch. 2002, 98, 176-183.

12. Larson, R.A. The antioxidants of higher plants. Phytochemistry 1988, 27, 969-978.

13. Heldt, H.W. Plant Biochemistry and Molecular Biology; Oxford Univ. Press: New York, NY, USA, 1997; p. 522.

14. Rice-Evans, C.A.; Miller, N.J.; Bolwell, P.G.; Bramley, P.M.; Pridham, J.B. The relative antioxidant activities of plant-derived polyphenolic flavonoids. Free Radical Res. 1995, 22, 375-383.

15. Chen, Q.; Shi, H.; Ho, C. Effects of Rosemary Extracts and Major Constituents on Lipid Oxidation and Soybean Lipoxygenase Activity. J. Am. Oil Chem. Soc. 1992, 69, 999-1002.

16. Kaufmann, B.; Christen, P. Recent Extraction Techniques for Natural Products: Microwaveassisted Extraction and Pressurised Solvent Extraction. Phytochem. Anal. 2002, 13, 105-113.

17. Bicchi, C.; Binello, A. Rubiolo, P. Determination of Phenolic Diterpene Antioxidants in Rosemary (Rosmarinus officinalis L.) with Different Methods of Extraction and Analysis. Phytochem. Anal. 2000, 11, 236-242.

18. Ganzler, K.; Salgo, A.; Valko, K. Microwave extraction-a novel sample preparation method for chromatography. J. Chromatogr. 1986, 371, 299-306.

19. Pan, X.; Niu, G.; Liu, H. Microwave-assisted extraction of tea polyphenols and tea caffeine from green tea leaves. Chem. Eng. Process 2003, 42, 129-133.

20. Hong, N.; Yaylayan, V.A.; Raghavan, G.S.V.; Paré, J.R.J.; Bélanger, J.M.R. Microwave assisted extraction of phenolic compounds from grape seed. Nat. Prod. Res. 2001, 15, 197-204.

21. Martino, E.; Ramaiola, I.; Urbano, M.; Bracco, F.; Collina, S. Microwave-assisted extraction of cumarin and related compounds from Melilotus officinalis (L.) Pallas as an alternative to Soxhlet and ultrasound-assisted extraction. J. Agric. Food Chem. 2006, 1125, 147-151. 
22. Waksmundzka-Hajnos, M.; Petruczynik, A.; Dragan, A.; Wianowska, D.; Dawidowicz, A.L.; Sowa, I. Influence of the extraction mode on the yield of some furanocoumarins from Pastinaca sativa fruits. J. Chromatogr. B 2004, 800, 181-187.

23. Mattina, M.J.I.; Berger, W.A.I.; Denson, C.L. Microwave-Assisted Extraction of Taxanes from Taxus Biomass. J. Agric. Food Chem. 1997, 45, 4691-4696.

24. Dai, J.; Yaylayan, V.; Raghavan, G.; Pare, J. Extraction and colorimetric determination of azadirachtin related limonoids in neem seed kernel. J. Agric. Food Chem. 1999, 47, 3738-3742.

25. Pan, X.; Liu, H.; Jia, G.; Shu, Y.Y. Microwave-assisted extraction of glycyrrhizic acid from licorice root. Biochem. Eng. J. 2000, 5, 173-177.

26. Pan, X.; Niu, G.; Liu, H. Comparison of microwave-assisted extraction and conventional extraction techniques for the extraction of tanshinones from Salvia miltiorrhiza bunge. Biochem. Eng. J. 2002, 12, 71-77.

27. Hao, J.; Han, W.; Huang, S.; Xue, B.; Deng, X. Microwave-assisted extraction of artemisinin from Artemisia annua L. Sep. Purif. Technol. 2002, 28, 191-196.

28. Shu, Y.Y.; Ko, M.Y.; Chang, Y.S. Microwave-assisted extraction of ginsenosides from ginseng root. Microchem. J. 2003, 74, 131-139.

29. Proestos, C.; Chorianopoulos, N.; Nychas, G.J.E.; Komaitis, M. RP-HPLC Analysis of the Phenolic Compounds of Plant Extracts. Investigation of Their Antioxidant Capacity and Antimicrobial Activity. J. Agric. Food Chem. 2005, 53, 1190-1195.

30. Shan, B.; Cai, Y.Z.; Sun, M.; Corke, H. Antioxidant capacity of 26 spice extracts and characterization of their phenolic constituents. J. Agric. Food Chem. 2005, 53, 7749-7759.

31. Prakash, D.; Suri, S.; Upadhyay, G.; Singh, B.N. Total phenol, antioxidant and free radical scavenging activities of some medicinal plants. Int. J. Food Sci. Nutr. 2007, 58, 18-28.

32. Prasad, K.N.; Yang, B.; Dong, X.; Jiang, G.; Zhang, H.; Xie, H.; Jiang, Y. Flavonoid contents and antioxidant activities from Cinnamomum species. Innov. Food Sci. Emerg. Technol. 2009, 10, 627-632.

33. Su, L.; Yin, J.J.; Charles, D.; Zhou, K.; Moore, J.; Yu, L. (Lucy). Total phenolic contents, chelating capacities and radical-scavening properties of black peppercorn, nutmeg, rosehip, cinnamon and oregano leaf. J. Agric. Food Chem. 2007, 100, 990-997.

34. Politeo, O.; Jukić, M.; Miloš, M. Chemical Composition and Antioxidant Activity of Essential Oils of Twelve Spices Plants. Croatia Chem. Acta 2006, 79, 545-552.

35. Tomaino, A.; Cimino, F.; Zimbaletti, V.; Venuti, V.; Sulfaro, V.; De Pasquale, A.; Saija, A. Influence of heating on antioxidant activity and the chemical composition of same spices essential oils. J. Agric. Food Chem. 2005, 89, 549-554.

36. Pellegrini, N.; Serafini, M.; Salvatore, S.; Del Rio, D.; Bianchi, M.; Brighenti, F. Total antioxidant capacity of spices, dried fruits, nuts, pulses, cereals and sweets consumed in Italy assessed by three different in vitro assays. Mol. Nutr. Food Res. 2006, 50, 1030-1038.

37. Re, R.; Pellegrini, N.; Proteggente, A.; Pannala, A.; Yang, M.; Rice-Evans, C. Antioxidant activity applying an improved ABTS radical cation decolorization assay. Free Radical Biol. Med. 1999, 26, 1231-1237.

38. Yen, G.C.; Chen, H.Y. Antioxidant activity of various tea extracts in relation to their antimutagenicity. J. Agric. Food Chem.1995, 43, 27-32. 
39. Benzie, I.F.F.; Strani, J.J. The ferric reducing ability of plasma (FRAP) as a measure of "antioxidant power": The FRAP assay. Anal. Biochem. 1996, 239, 70-76.

40. Gao, X.; Ohlander, M.; Jeppsson, N.; Björk, L.; Trajkovski, V. Changes in antioxidant effects and their relationship to phytonutrients in fruits of sea buckthorn (Hippophae rhamnoides L.) during maturation. J. Agric. Food Chem. 2000, 48, 1485-1490.

Sample Availability: Samples of the compounds are available from the authors.

(C) 2010 by the authors; licensee MDPI, Basel, Switzerland. This article is an open access article distributed under the terms and conditions of the Creative Commons Attribution license (http://creativecommons.org/licenses/by/3.0/). 